\title{
FOLIC ACID DEFICIENCY
}

\author{
E. V. Cox, M.D., B.Sc., M.R.C.P. \\ Senior Medical Registrar \\ M. J. Meynell, M.D., F.R.C.P., D.P.H. \\ Pathologist \\ W. T. CoOke, M.D., F.R.C.P. \\ Physician
}

From the General Hospital, Birmingham

MACrocyTIC anæmia, associated with a megaloblastic erythropoiesis, glossitis, weight loss, diarrhœa, and an absence of neurological symptoms or signs and of evidence of deficiency of vitamin $B_{12}$ are usually accepted as the features of deficiency of folic acid or related pteroylglutamate compounds. Such an assumption is based on the clinical and hæmatological remission induced by the administration of a synthetic compound, folic acid. The term 'folic acid' also stands for the family of conjugated pterins and pteridines having 'folic' biological activity (Hutner, Nathan and Baker, 1959). The clinical picture occurs in malnutrition, in certain diseases of the small intestine, such as cœliac disease, tropical sprue or jejunitis from various causes, and in pregnancy. Sometimes it follows treatment with anti-folic compounds, such as aminopterin, or with certain anti-convulsant drugs, such as primidone, phenobarbitone, epanutin or mysoline. Because of the variety of conditions in which deficiency of folic acid occurs, it is thought that it is the result of a poor intake, poor absorption, increased demand created by a disordered metabolism, or a combination of these factors.

\section{Diagnosis of Folic Acid Deficiency \\ I. Hamatological Diagnosis}

A megaloblastic anæmia with a normal level of vitamin $B_{12}$ in the serum, or not responding adequately to parenteral administration of vitamin $\mathbf{B}_{12}$ but with complete remission with folic acid therapy, still remains the most satisfactory conclusive proof.

\section{Microbiological Assay in Blood and Tissues}

Assays using Streptococcus facalis or Lactobacillus casei are available and relatively simple. Results are difficult to interpret, however, as will be appreciated when considering the demonstra- tion by Usdin (1959) of at least nine pteroylglutamate fractions, chromatographically distinct, in the $N$ blood. The microbiological activity of these frac- i tions varies and none of them has been identified $N$ with certainty with known chemical members of $\frac{\mathrm{O}}{2}$ the pteroylglutamate complex. The manner in which folic acid activity is released prior to assay can affect the results obtained. Moreover, Toennies and Phillips (1959), using whole bloo $\vec{\mathscr{}}$ nave shown that there are substances in red cellg which release folic acid activity (F.A.A.) from the plasma.

Using Streptococcus facalis, we were unable to show any consistent difference in F.A.A. between the blood and material from the bone marrow in normal subjects and in patients with deficiencies of either folic acid or vitamin $\mathrm{B}_{12}$ (Cox, Matthews, Meynell, Cooke and Gaddie, I96oa). Also it must be emphasized that blood folic acid activity is spontaneously increased during active blood regeneration (Cox, Meynell, Cooke and Gaddie, 1960b). Following hæmorrhage, acute or chronic, blood folic acid activity rises for many days and falls to normal levels only when the blood picture has returned to normal. A similar phenomenon occurs following specific therapy with vitamin $B_{12}$ 을 or with iron. Furthermore, in patients with clinical evidence of deficiency of folic acid an initial rise of F.A.A. falling to pre-treatment levels occurs following the administration of folic acid, o only to be followed by a secondary rise in F.A.A., N subsequent to the reticulocytosis, which persists for some time before falling to normal levels coincident with the restoration of the blood picture to normal. Such observations must influence the $\frac{0}{\Phi}$ interpretation of ' resting' blood levels. We were $\stackrel{\mathscr{D}}{?}$ unable to find any correlation between the blood 7 and bone marrow content of folic acid activity (Cox et al., r960).

Recently Herbert, Baker, Frank, Pasher, $\frac{\circ}{\mathbb{Q}}$ 
Sobotka and Wasserman (1960) have described a method of folic acid assay on serum using Lactobacillus casei, which, they claim, correlates with the clinical conditions of folic acid deficiency when abnormally low serum levels are found, in contrast to the findings in patients with deficiency of vitamin $B_{12}$. We have not been able to substantiate this claim using Streptococcus facalis. The probability is that these organisms, $L$. casei and $S$. facalis, do not measure the same thing. Much more work is necessary before diagnostic significance can be placed on the serum levels.

\section{Urinary Excretion of Test Doses of Folic Acid}

The urinary excretion of folic acid following parenteral (intramuscular) administration has not proved satisfactory. Some patients with apparent clinical deficiency excrete normal amounts of folic acid (Girdwood, 1956; Cox, Meynell, Cooke and Gaddie, I958a), whilst approximately $50 \%$ of patients with pernicious anæmia had a reduced excretion (Girdwood, 1956; Cox, Meynell, Cooke and Gaddie, 1958b). Two factors need consideration in this context. The amount of folic acid necessary to saturate the 'enzymatic systems' is probably very small and less than the differences that can be readily detected in the urine. Secondly, the unsaturation of tissues, such as muscle, does not bring about the clinical signs of folic acid deficiency. Thus many elderly patients on poor diets, but without hæmatological abnormality, will excrete low quantities of folic acid following similar test doses. It seems probable that the poor dietary intake of many patients with pernicious anæmia similarly leads to tissue depletion of folic acid.

\section{Clearance of Intravenously Administered Folic Acid}

Chanarin, Mollin and Anderson (1958a) observed an increased rate of clearance from the plasma of folic acid ( $15 \mu \mathrm{g}$. per kg.) administered intravenously in patients with folic acid deficiency. However, similar rates of clearance were observed in patients with deficiency of vitamin $B_{12}$ (varying with the degree of anæmia), hæmolytic anæmia and in some patients with iron deficiency. Increased rates of clearance were also recorded in a proportion of normal pregnancies. The increased rate of clearance in such disorders could be due to tissue depletion, to increased demand owing to the abnormal or increased hæmatopoeisis or to excessive utilization associated with the disturbed metabolism of folic acid deficiency.

\section{Urinary Excretion of Formiminoglutamic Acid (FIGLU)}

Formiminoglutamic acid (FIGLU) is excreted in the urine in increased amounts in folic acid deficiency (Broquist, 1956). Tetrahydropteroyl-. glutamic acid is required for the conversion of FIGLU to glutamic acid (Miller and Waelsch, 1957). Methods for estimating FIGLU in the urine are not sufficiently sensitive to differentiate between the patients with pernicious anæmia and those with folic acid deficiency. Since FIGLU is a breakdown product of histidine, preliminary loading with this amino acid permits the differentiation between the urinary excretion of FIGLU by folic acid-deficient and replete patients (Luhby, Cooperman and Teller, 1959). Though these findings have been confirmed by a number of workers, exceptions have already been noted (Herbert, 1959). Increased excretion of FIGLU has been noted in vitamin $\mathrm{B}_{12}$-deficient rats despite adequate intake of folic acid. Increased amounts have also been found in the urine of patients with apparently uncomplicated pernicious anæmia (Marshall and Jandl, 1960).

\section{Aminoaciduria}

An abnormal pattern of urinary excretion of amino acids has been reported in patients with megaloblastic anæmia with the suggestion that it might be of importance in differential diagnosis. While confirming the frequent occurrence of such patterns, we had similar results in hypochromic anæmia due to iron deficiency and inconsistent differences between the megaloblastic anæmias due to folic acid deficiency and those due to deficiency of vitamin $\mathrm{B}_{12}$ (Fowler, Cox, Cooke and Meynell, 1960).

\section{Folic Acid Excretion Test}

This test is based on the principle that comparison between the amounts of folic acid excreted in the urine after an intramuscular dose and those after an oral dose of folic acid should bear a close relationship to the ability to absorb folic acid from the intestine. In practice a normal subject following $5 \mathrm{mg}$. folic acid, either orally or intramuscularly, excretes approximately similar amounts. The amount excreted after an oral dose, expressed as a percentage of that excreted after an intramuscular dose given 48 hours previously, is referred to as the excretion index. In normal subjects this is around $100 \%$ and varies from 70 to $120 \%$. Over $90 \%$ of patients with adult coliac disease or idiopathic steatorrhœa have low indices. Patients with regional enteritis affecting the jejunum also have low indices, a finding which has led to the suggestion that folic acid is absorbed through the jejunum. The test is normal in pernicious anæmia and in the majority of patients with megaloblastic anæmia of pregnancy. It is also normal in patients with steatorrhœa due to pancreatic disorders, gastric operations and regional 
enteritis when the upper small intestine is normal (Cox et al., 1958a).

\section{Oral Folic Acid Tolerance Curves}

All tolerance curves are justly criticized because they are not only influenced by the amount of absorption, but also, and probably to a greater extent, by the rate of absorption and the rate of clearance from the blood stream. Chanarin, Anderson and Mollin (1958b) have found the plasma folic acid levels following $3 \mathrm{mg}$. folic acid orally a satisfactory means of determining defective absorption of folic acid in patients with idiopathic steatorrhœa. They did, however, find similar curves in pregnant patients, both in late normal pregnancy as well as those with megaloblastic anæmia. They suggest that this may be of ætiological significance in the production of megaloblastic anæmia of pregnancy (Chanarin, MacGibbon, O'Sullivan and Mollin, 1959).

\section{Tritium-labelled Folic Acid}

Anderson, Belcher, Chanarin and Mollin (1960) have used tritium-labelled folic acid in the investigation of folic acid deficiency. Following oral administration of $0.2 \mathrm{mg}$. or $40 \mu \mathrm{g}$. $/ \mathrm{kg}$. ${ }^{3} \mathrm{H}$ folic acid, the fæcal excretion was usually less than $25 \%$ in normal patients and greater than $50 \%$ in patients with idiopathic steatorrhœa. The urinary excretion of radioactive material, especially when enhanced by a preliminary dose of $15 \mathrm{mg}$. folic acid intramuscularly, was also considered reliable in demonstrating 'malabsorption'. It could be done more rapidly and less laboriously than fæcal estimations. They did point out that the frcal excretion was quantitative and the difference between the amounts excreted in the fres and those in the urine were still considerable. Endogeneous factors could cause significant errors in interpretation when based on urinary excretion only.

\section{The Ftiology of Folic Acid Deficiency}

Deficient diet, impaired absorption, increased demand and defective utilization cover in general terms the possible factors. A combination of any of these is not uncommon. For example, green vegetables, a major dietary source of pteroylglutamates, may exacerbate alimentary symptoms and be avoided by patients with coliac disease and idiopathic steatorrhæa; in pregnancy, when an increased demand is to be expected, disturbance of dietary habits or nausea and vomiting can reduce the intake of folic acid. Defective utilization of folic acid may not only be encountered during anti-folic therapy, but also in pregnancy and in coeliac disease. Other deficiencies, such as iron and ascorbic acid, may aggravate the disturbance (Cox et al., 1960).
It is evident that folic acid deficiency must be considered from two points of view. The first if that the tissues may contain pteroylglutamates reduced in quantity to such a degree that a dis $\underset{\Omega}{\mathbb{D}}$ turbed metabolism results. An alternative possic. bility exists when the tissue content of pteroyl glutamates is normal, but its metabolic activity is in some way disturbed or blocked so that the normal requirement is increased. Treatment witt: anti-folic compounds, and possibly the anti $\frac{\bar{\sigma}}{\bar{\sigma}}$ convulsant drugs mentioned, might be example\& of this second possibility. These two types of deficiency may account for the contradictory find $\overrightarrow{0}$ ings reported in other conditions associated witk folic acid deficiency.

It seems logical that patients presenting wit令 the severe anæmia and obvious clinical manifestao tions of folic acid deficiency, particularly in adult cœliac disease and idiopathic steatorrhœa, would్ show greater degrees of malabsorption of folif acid than those not so severely affected. How ever, as judged from the folic acid excretion test: and the oral tolerance curves following the $\mathrm{ad}_{\mathrm{O}}^{\mathrm{N}}$ ministration of $5 \mathrm{mg}$. folic acid by mouth, the converse appears to be true. Using tritium-labelled folic acid, Anderson, Belcher, Chanarin and Molli变 (1960) have made similar observations, i.e. that the patients with severe megaloblastic anærhis absorbed folic acid rather better. Fone, Cooke, Meynell, Brewer, Harris and Cox (1960) fous that the majority of patients with a severe mega blastic anæmia and steatorrhœe did not have the complete flattening of the jejunal villi seen i⿺辶巛 cœliac disease. In view of the shorter clinicas history and other small differences, it might b $\vec{\delta}$ postulated that in some of these patients there was a fundamental ætiological distinction and that mal absorption is not the complete explanation. It is also of great interest that patients in this group have complete clinical and hæmatological re 3 . mission lasting many months and up to more than? five years following the administration of only $5 \mathrm{mg}$. folic acid, the performance of a folic aci\$ excretion test or to the single injection of $5 \mathrm{mg}$. citrovorum factor.

Megaloblastic anæmia of pregnancy poses some $\rightarrow$ what similar questions. The generally acceptes. view that megaloblastic anæmia of pregnancy ins temperate zones is the result of a pteroylglutamate deficiency in the strict sense is open to doubto Girdwood (1956) found the folic acid excretion test in many of these patients was normal; ip approximately half, however, there was a reduced urinary excretion of folic acid following the intrae muscular test dose. Cox et al. (1960) encounterecf one patient with megaloblastic anæmia of preg nancy in whom the concentrations of folic acis activity, ascorbic acid and vitamin $B_{12}$ were norma 
in both the blood and narrow cells. Thompson and Ungley (I95 I) found that some anæmic patients with no alimentary dysfunction were taking better diets than other pregnant women who had no anæmia or disorder of folic acid metabolism. Again a single injection of $5 \mathrm{mg}$. folic acid may be sufficient to bring about complete hæmatological remission.

The effect of folic acid antagonists in causing megaloblastic reversion of the bone marrow was first noted by Stickney in 1952. Following this lead, it seemed possible that anticonvulsant drugs might act similarly. Badenoch (1954), closely followed by Hawkins and Meynell (1954), were the first to record this phenomenon. Subsequently, many similar examples have been recorded. Hawkins and Meynell (1958) reported detailed investigations on eight patients. In all serum levels of vitamin $B_{12}$ were normal, as were the folic acid excretion tests. The bone marrow and peripheral blood pictures were indistinguishable from those found in pernicious anæmia. Despite normal serum levels, some of the patients improved with vitamin $B_{12}$. All, however, attained hæmatological remission with folic acid; a daily dose of 5 to 10 mg. given with the anticonvulsant drug provides complete protection. Girdwood and Lenman (1956) pointed out the structural similarities between folic acid, primidone, phenobarbitone and phenytoin. The precise action of the anticonvulsant drugs is not yet fully understood, but it has been suggested that they act as enzyme inhibitors.

\section{The Pteroylglutamates and Pernicious Anæmia}

Megaloblastic anæmias are due to deficiency either of cyanocobalamin or of folic acid. Whilst those due to folic acid deficiency respond to small doses of folic acid, those due to vitamin $B_{12}$ deficiency do manifest hæmatological response to larger doses of folic acid. It has long been known that patients with pernicious anæmia will respond to folic acid in relatively large doses, though this therapy does not prevent neurological complications. Evidence of a tissue depletion of folic acid has been shown in pernicious anæmia. Low F.A.A., as assayed with $S$. facalis, occurs in approximately $50 \%$ (Nieweg, Faber, DeVries and Kroese, 1954; Cox et al., r960). The urinary excretion following $5 \mathrm{mg}$. folic acid is reduced in a similar number (Cox et al., 1958). The plasma clearance of intravenously administered folic acid is increased proportionate to the degree of anæmia (Chanarin et al., 1958a). On the other hand, folic acid is rarely required to supplement vitamin $B_{12}$ therapy in the treatment of pernicious anæmia (Ungley, 1955). Following $B_{12}$ therapy, a retention of folic acid by the body takes place, usually after the maximum reticulocytosis, and is associated with a rise in F.A.A. of the blood. The theory put forward by Vilter and his colleagues (1950) to explain the effect of folic acid in vitamin $B_{12}$ deficient states as a 'mass action' effect seems possible, though not very enlightening. At this stage it must be admitted that the interrelationships of folic acid and vitamin $B_{12}$ are poorly understood.

\section{Requirements of the Pteroylglutamates}

No mention has yet been made of the normal daily requirements of folic acid in man, for data have been inadequate. Jandl and Lear (1956), basing their calculations on the daily urinary excretion, suggested that the requirements do not exceed 0.2 to $0.3 \mathrm{mg}$. per day. Marshall and Jandl (1960) used dosages of folic acid of this order (0.4 mg.) intramuscularly daily to distinguish between megaloblastic anæmias due to folic deficiency and those due to cyanocobalamin deficiency. Such small ' physiological ' doses brought about hæmatological remission in 'folic acid deficiency', but had little or no effect in deficiency due to vitamin $B_{12}$. All that can be stated is that the requirements for folic acid in the normal are considerably less than the doses, 5 to $15 \mathrm{mg}$. daily, usually given in clinical practice.

\section{Conclusion}

Though much has been written on this subject, our understanding of the metabolic activity of the pteroylglutamates is far from complete (Hutner et al., 1959). The only point of general agreement is that the active members are concerned with the transfer and utilization of single carbon moieties. It can be appreciated that there are many problems posed by what constitutes ' folic acid deficiency'. Difficulty arises from the lack of knowledge of the naturally occurring substances with 'folic acid' activity. Any attempt to identify what happens when folic acid, a synthetic substance, is administered with what has occurred in a particular disease is limited. Malutilization as well as deficiency must be considered.

\section{REFERENCES}

Anderson, B. B., Belcher, E. H., Chanarin, I., and Mollin, D. L. (1960): The Fæcal and Urinary Excretion of Radioactivity After Oral Doses of ${ }^{3} \mathrm{H}$-Folic Acid, Brit. F. Hamat., 6, 439.

Badenoch, J. (1954): The Use of Labelled $\mathrm{B}_{12}$ and Gastric Biopsy in the Investigation of Anæmia, Proc. Roy. soc. Med., 47,426 . 
BroQuist, H. B. (1956): Evidence for the Excretion of Formiminoglutamic Acid Following Folic Acid Antagonis Therapy in Acute Leukæmia, f. Amer. chem. Soc., 78, 6205.

Chanarin, I., Mollin, D. L., and Anderson, B. B. (1958a): The Clearance from the Plasma of Folic Acid Injected Intravenously in Normal Subjects and Patients with Pernicious Anæmia, Brit. Y. Hamat., 4, 435.

-, Anderson, B. B., and Mollin, D. L. (1958b): The Absorption of Folic Acid, Ibid., 4, 156. , MacGibbon, B. M., O'Sullivan, W. J., and Mollin, D. L. (1959): Folic Acid Deficiency in Pregnancy. The. Pathogenesis of Megaloblastic Anæmia of Pregnancy, Lancet, ii, 634.

Cox, E. V., MATthews, D., MEYNELl, M. J., CookE, W. T., and GADDIE, R. (1960a): Cyanocobalamin, Ascorbic Acid and Pteroylglutamates in Normal and Megaloblastic Bone Marrow, Blood, 15, 376.

-, Meynell, M. J., Cooke, W. T., and Gaddie, R. (1960b): Folic Acid Activity During Blood Regeneration.

\begin{tabular}{ll} 
Clin. Sci., 19, 219. \\
,- \\
\hline
\end{tabular}

Fone, D. J., Cooke, W. T., MeYnell, M. J., Brewer, D. B., Harris, E. L., and Cox, E. V. (1960): Jejunal Biopsy in Adult Coliac Disease and Allied Disorders, Lancet, $\mathbf{i}, 933$.

Fowler, D. I., Cox, E. V., Cooke, W. T., and Meynell, M. J. (1960): Aminoaciduria and Megaloblastic Anæmia, $\vec{O}$ f. clin. Path., 13, 230.

GirDwood, R. H. (1956): The Megaloblastic Anæmias, Quart. F. Med., 25, 87.

, and Lenman, J. A. (1956): Megaloblastic Anæmia Occurring During Primidone Therapy, Lancet i, 146.

Hawkins, C. F., and Meynell, M. J. (1954): Megaloblastic Anæmia Due to Phenytoin Sodium, Ibid., 2, 737.

- (1958): Macrocytosis and Macrocytic Anæmia Caused by Anticonvulsant Drugs, Quart. $\mathscr{F}$. Med., $27,45$.

Herbert, V. (1959): 'Megaloblastic Anæmias'. New York and London: Grune and Stratton.

Herbert, V., Baker, H., Frank, O., Pasher, I., Sobotka, H., and Wasserman, L. R. (1960): The Measurement of Folic Acid Activity in Serum. A Diagnostic Aid in the Differentiation of the Megaloblastic Anæmias, Blood, i $15,228$.

Hutner, S. H., Nathan, H. A., and Baker, H. (1959): Metabolism of Folic Acid and Other Pterin-Pteridine Vitamins, Vitam. and Horm., $17, \mathrm{I}$.

JANDl, J. H., and Lear, A. A. (1956): The Metabolism of Folic Acid in Cirrhosis, Ann. intern. Med., 45, 1027.

Luhby, A. L., Cooperman, J. M., and Teller, D. N. (I959): Urinary Excretion of Formiminoglutamic Acid, Amer. 7. clin. Nutr., 7, 397.

Marshall, R. A., and JANDL, J. H. (1960): Responses to 'Physiological' Doses of Folic Acid in the Megaloblastic Anæmias, Arch. intern. Med., 105, 352.

Miller, A. and WAELSCH, H. (1957): Formimino Transfer from Formamidinoglutaric Acid to Tetrahydrofolic Acid, F. biol. Chem., 228, 397.

NiewEG, H. O., FABER, J. G., DeVries, J. A., and Kroese, W. F. S. (1954): The Relationship of Vitamin $B_{12}$ and Fo Acid in Megaloblastic Anæmia, F. Lab. clin. Med., 44, 118.

StickNeY, J. M. (1952): Proceedings of the Second Conference on Folic Acid Antagonists in the Treatment Leukæmia, Blood, 7, sup. 114.

Thompson, R. B., and UngLEY, C. C. (195I): Megaloblastic Anæmia of Pregnancy and the Puerperium, Quart. F. Med 20, 187.

Toensies, G., and Phillips, P. M. (1959): Resolution of Precursor and Enzyme Fractions of the Blood Folic Acid System, Э. biol. Chem., 234, 2369.

UngLeY, C. C. (1955): The Chemotherapeutic Action of Vitamin $\mathrm{B}_{12}$, Vitam. and Horm., r3, 137.

UsDin, E. (1959): Blood Folic Acid Studies, F. biol. Chem., 234, 2373.

Vilter, R. W., Horrigan, D., Mueller, J. F., Jarrold, T., Vilter, C. F., Hawkins, V., and Seaman, A. (1950): Studies on the Relationships of Vitamin $B_{12}$, Folic Acid, Thymine, Uracil and Methyl Donors in Persons with Pernicious Anæmia and Related Megaloblastic Anæmia, Blood, 5, 695. 